\title{
Preparation and structural characterization of sol-gel-derived silver silica nanocomposite powders
}

\author{
Duy Phong Pham ${ }^{1}$, Kim Khanh Huynh ${ }^{2}$, Cao Vinh Tran ${ }^{1}$, Van Quang Vu ${ }^{3}$, \\ Thi Thanh Van Tran ${ }^{2, *}$ \\ ${ }^{1}$ Laboratory of Advanced Materials, University of Science, Vietnam National University Ho Chi Minh City, Vietnam \\ ${ }^{2}$ Faculty of Materials Science, University of Science, Vietnam National University Ho Chi Minh City, Vietnam \\ ${ }^{3}$ International Training Institute for Material Science (ITIMS), Hanoi University of Science and Technology (HUST), Hanoi, Vietnam
}

\section{Email address:}

pdphong@hcmus.edu.vn (D. P. Pham), tttvan@hcmus.edu.vn (T. T. V. Tran)

\section{To cite this article:}

Duy Phong Pham, Kim Khanh Huynh, Cao Vinh Tran, Van Quang Vu, Thi Thanh Van Tran. Preparation and Structural Characterization of Sol-Gel-Derived Silver Silica Nanocomposite Powders. International Journal of Materials Science and Applications.

Vol. 3, No. 5, 2014, pp. 147-151. doi: 10.11648/j.ijmsa.20140305.13

\begin{abstract}
The silver embedded silica powders $\left(\mathrm{Ag} / \mathrm{SiO}_{2}\right)$ have been successfully prepared by sol-gel method. $\mathrm{Ag}$ nanoparticles were formed from the thermal decomposition of the silver nitrate. X-ray diffraction shows that the silver nanocrystals have appeared after a heat-treatment at $600{ }^{\circ} \mathrm{C}$. TEM images show that the spherical silver particles with an average size around $30 \mathrm{~nm}$ dispersed homogeneously in silica matrix. The data of XRD, Raman and FTIR spectroscopy prove that the formation of the silver nanocrystals influent on the structural evolution of the silica matrix. The presence of metal nanocrystals leads to remarkable decrease in crystallizing temperature of $\mathrm{SiO}_{2}$. In addition, the adsorption-desorption analysis indicated that the growth of Ag particles makes the pores in silica structure widen.
\end{abstract}

Keywords: Silver Nanoparticles, Silica Phase Transformation, Raman Spectroscopy, $\mathrm{Ag} / \mathrm{SiO}_{2} \mathrm{Nano-Composite}$

\section{Introduction}

The nanocrystal silver particles have attracted the attention due to their widely potential applications in many fields such as catalysts, optoelectronics, the surface enhanced Raman scattering (SERS), chemical and biological sensing and especially known as the most common antibacterial materials ${ }^{1-4}$. The silver nanoparticles have been introduced into many different inorganic materials as $\mathrm{SiO}_{2}, \mathrm{TiO}_{2}, \mathrm{ZnO}, \mathrm{SiO}_{2}-\mathrm{TiO}_{2}{ }^{5-8}$. Of these, Ag-loaded $\mathrm{SiO}_{2}\left(\mathrm{Ag} / \mathrm{SiO}_{2}\right)$ has been known for its high chemical durability, safety and heat resistance. In addition, the $\mathrm{SiO}_{2}$ materials, known as porous structure, can adsorb various ions and organic molecules easily in its pores and on its surfaces. Because of this, it is expected to be one of the most promising carriers suitable for development of high performance antibacterial and bactericidal materials ${ }^{9}$. There are a lot of methods used to prepare $\mathrm{Ag} / \mathrm{SiO}_{2}$ nano-composites including sol-gel, sputtering, ion implantation, ion exchange, high-temperature glass fusion, etc. ${ }^{8,10-12}$. Among these methods, the sol-gel has several advantages such as high purity, ultra-homogeneity, low synthesis temperature, and most significantly the possibility of making glasses of new compositions ${ }^{13}$.

In order to prevent the aggregation of silver nanoparticles (NPs) into clusters the protecting agents or stabilizers, which are amphiphilic, polymer polyvinyl pyrrolidone (PVP) ${ }^{14}$, poly(vinyl alcohol) (PVA) ${ }^{15}$, Sodium Dodecyl Sulphate (SDS), or Citrate of sodium ${ }^{16}$, were used in synthesis process. However, these additional agents can result in complex synthesis process, toxicity, and higher cost. That why a synthesis process without PVP, PVA or SDS attracts attention for economic industrial applications.

A silica matrix also can be used as an agent in order to prevent the aggregation of silver particles. Moreover, due to the unknown health risks of metal NPs, they are necessary to be tightly attached; hence their diffusion to the environment is inhibited. Many authors prepared silver nanoparticles in silica matrix under different forms such as rods ${ }^{17}$, powders ${ }^{11,18}$ or monoliths ${ }^{19,20}$ for antibacterial applications.

This work presents a collection of data obtained for sol-gel-derived $\mathrm{SiO}_{2}-5 \mathrm{~mol} \%$ silver nano-composites powders without protecting agents, which are developed for applications in antibacterial and environment. In this study, 
the formation of silver crystals as a function of annealing temperatures and their effect on the structural evolution of silica matrix were also demonstrated.

\section{Experiment}

\subsection{Sample Preparation}

$\mathrm{Ag} / \mathrm{SiO}_{2}$ nano-composite powders with $5 \mathrm{~mol} \%$ silver were prepared by sol-gel method. The precursors consisted of tetraethyl orthosilicate (TEOS, $\mathrm{Si}\left(\mathrm{OC}_{2} \mathrm{H}_{5}\right)_{4}$, Merck), silver nitrate $\left(\mathrm{AgNO}_{3}\right.$, Merck), ethanol $\left(\mathrm{C}_{2} \mathrm{H}_{5} \mathrm{OH}\right.$, Merck), nitric acid $\left(\mathrm{HNO}_{3}\right.$, Merck), and distilled water. The molar ratio of TEOS: $\mathrm{C}_{2} \mathrm{H}_{5} \mathrm{OH}: \mathrm{HNO}_{3}: \mathrm{H}_{2} \mathrm{O}$ was 1: 4: 0.15: 10, respectively. In the first step, amount of $\mathrm{AgNO}_{3}$ and distilled water were mixed and stirred for $30 \mathrm{~min}$ at room temperature to form A-solution. In another beaker, TEOS and ethanol were also mixed for 30 minutes to obtain B-solution. Then, B-solution was slowly poured into A-solution under stirring. After 30 min stirring, this mixture was added by $\mathrm{HNO}_{3}$, ethanol and $\mathrm{H}_{2} \mathrm{O}$. The finally mixed solution was continuously stirred for 4 hours at room temperature and then placed into sealed polypropylene containers. The gelation occurred in air after one week. The obtained bulk samples were grinded into fine powders. These powders were annealed in air at various temperatures from $300{ }^{\circ} \mathrm{C}$ to $1000{ }^{\circ} \mathrm{C}$ for 1 hour.

\subsection{Characterization}

The crystalline phases of the powders were characterized by XRD patterns using a D8 Advance (Bruker) X-ray diffractometer (XRD) with $\mathrm{Cu} K \alpha$ radiation $(\lambda=0.154 \mathrm{~nm})$. The morphology of samples were recorded by the transmission electron microscopy (TEM, JEM-1400, Japan).

The pore sizes and the distributions of pores as well as the specific surface area were deduced from the nitrogen adsorption and desorption measurements according to $\mathrm{BJH}$ model using Micromeritics porosimeter.

The effect of annealing temperatures and silver nanocrystals on the structural evolution of silica matrix were studied by spectroscopic measurements. The IR transmission were examined by EQUINOX 55 (BRUKER) in the range of $4000-400 \mathrm{~cm}^{-1}$ using potassium bromide $(\mathrm{KBr})$-based pellets. These pellets were prepared by mixing $\mathrm{KBr}$ powder and $\mathrm{Ag}-\mathrm{SiO}_{2}$ powder with a ratio of 130:1, respectively. By using a Renishaw instrument, Raman spectra of powders under an excitation wavelength at $633 \mathrm{~nm}$ were recorded.

\section{Results and Discussion}

\subsection{Crystallization of Silver and Silica}

$\mathrm{X}$-ray diffraction patterns of powders annealed from 400 ${ }^{\circ} \mathrm{C}$ to $1000{ }^{\circ} \mathrm{C}$ are revealed in Fig. 1. It is seen that no peaks characterized for silver crystal phase are present at temperatures below $500{ }^{\circ} \mathrm{C}$. After a heat-treatment at $600{ }^{\circ} \mathrm{C}$, the appearance of a weak peak at $2 \theta=38^{\circ}$ is assigned to the (111) planes of silver crystals. At higher temperatures, in addition to the peak at $38^{\circ}$, peaks at $2 \theta=44.6,64.6$ and $77^{\circ}$, which correspond to (200), (220), and (311) planes of silver face-centered cubic phase (JCPDS No. 04-0783), appear clearly. The increase in intensity of peaks with annealing temperatures, accompanied by a decrease in peak width, attests to the increase in grain size.

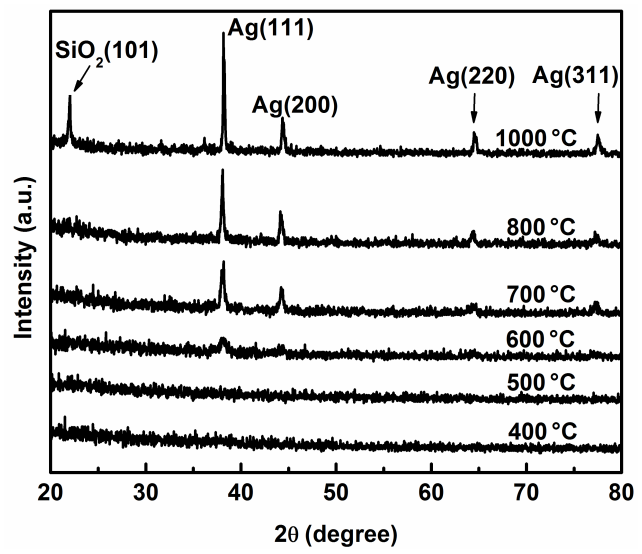

Figure 1. XRD patterns of the $\mathrm{SiO}_{2}-5 \% \mathrm{Ag}$ powders heat-treated at different temperatures for $1 \mathrm{~h}$.

The average diameter of the silver particles was calculated from the diffraction peaks using Scherrer's formula:

$$
\mathrm{D}=\frac{0.9 \lambda}{\beta \cdot \cos \theta}
$$

where $\mathrm{D}$ is mean crystallite size, $\beta$ is the width of the peak at half maximum intensity of a specific phase in radians, and $\lambda$ is the wavelength of incident rays, $\theta$ is the center angle of the peak in radian. The mean crystallite size for silver nanoparticles was evaluated to be 20 and $35 \mathrm{~nm}$ for samples heat-treated at $600^{\circ}$ and $1000^{\circ} \mathrm{C}$, respectively.

Moreover, the appearance of a new intense peak at $2 \theta=$ $22^{\circ}$ in the top diffraction pattern is assigned to (101) planes in cristobalite structure of silica. This observation denotes that the crystallization of silica occurs around $1000{ }^{\circ} \mathrm{C}$, while that of pure silica systems begins at $1400{ }^{\circ} \mathrm{C}{ }^{21}$. It is suggested that the presence of metallic silver particles favors crystallization of sol-gel derived silica. According to the model suggested by L. L. Díaz-Flores et al., the near-to-metal atoms of a matrix will be in the vibrational state much different from the bulk atoms. This vibrational energy is sufficient to break the inter-atomic bonds, thus disrupting the amorphous network and reducing the kinetic barrier to the crystallization ${ }^{21,22}$.

A TEM image of the $5 \mathrm{~mol} \% \mathrm{Ag}$ powder heat-treated at $800^{\circ} \mathrm{C}$ is presented in Fig.2. showing a relatively homogenous distribution of $\mathrm{Ag}$ spherical particles throughout the amorphous silica network. In the studies of a very large number of images for $5 \mathrm{~mol} \% \mathrm{Ag}$ systems, the particle sizes range between 20 and $40 \mathrm{~nm}$ for samples 
heat-treated at $800^{\circ} \mathrm{C}$. This value correlates with that obtained from XRD data.

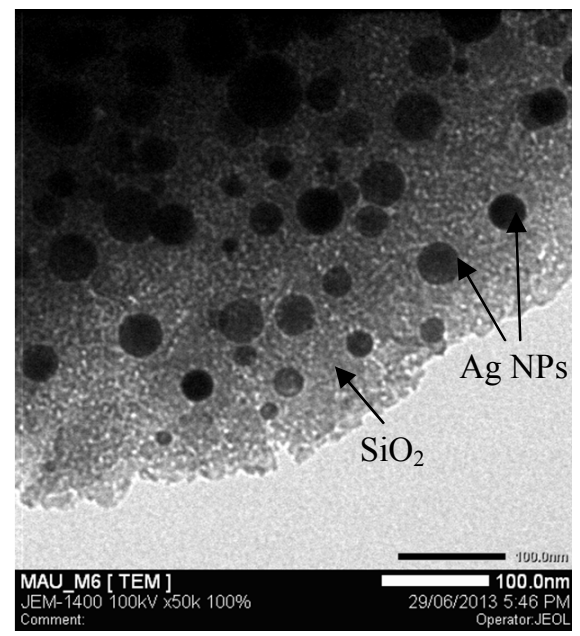

Figure 2. TEM images of a SiO2-5\%Ag sample after a heat-treatedment at $800^{\circ} \mathrm{C}$ for $1 \mathrm{~h}$

\subsection{Structural Evolutions of Silica Matrix}

\subsubsection{FTIR Spectroscopy}

Fourier transform infrared spectroscopy (FT-IR) was used to investigate the structural change of $\mathrm{SiO}_{2}$ as a function of annealing temperatures.

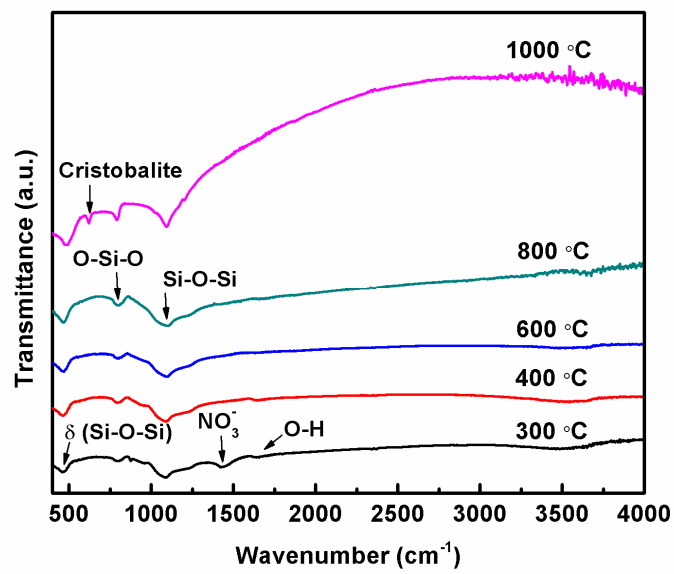

Figure 3. FT-IR spectra of the $\mathrm{SiO}_{2}-5 \% \mathrm{Ag}$ powders heat-treated at different temperatures for $1 \mathrm{~h}$

Fig. 3 shows the FT-IR transmission spectra for $5 \mathrm{~mol} \%$ powder samples heat-treated at various temperatures. The broad band observed around $3458 \mathrm{~cm}^{-1}$ and that at 1643 $\mathrm{cm}^{-1}$ are typical of vibrational modes involving $\mathrm{O}-\mathrm{H}$ groups of residual water and alcohol groups. The disappearance of $\mathrm{O}-\mathrm{H}$ groups at annealed temperatures above $600{ }^{\circ} \mathrm{C}$ confirms the elimination of hydroxyl or organic groups in the densified powders. The band at $1429 \mathrm{~cm}^{-1}$ is attributed to $\mathrm{NO}_{3}{ }^{-}$ions ${ }^{13}$. The gradual decrease of $\mathrm{NO}_{3}{ }^{-}$ions upon further increased annealing temperatures can be due to the strongly happened pyrolysis process of $\mathrm{AgNO}_{3}$, releasing the $\mathrm{Ag}$ atoms and $\mathrm{NO}_{2}$ gas. The strong band at $1088 \mathrm{~cm}^{-1}$ along with the accompanying shoulder at $1228 \mathrm{~cm}^{-1}$ is the asymmetric stretching vibration of $\mathrm{Si}-\mathrm{O}-\mathrm{Si}$ bonds linking of the $\mathrm{SiO}_{2}$ tetrahedra; the band at $804 \mathrm{~cm}^{-1}$ is assigned to $\mathrm{O}-\mathrm{Si}-\mathrm{O}$ modes, while the band at $454 \mathrm{~cm}^{-1}$ corresponds to the $\delta$ ( $\mathrm{Si}-\mathrm{O}-\mathrm{Si}$ ) bending mode ${ }^{13}$. With increasing annealing temperatures, no displacements to higher wavenumbers of all the bands related to polyhedral vibrations imply that the growing crystalline NPs have no effect on the densification of the $\mathrm{SiO}_{2}$ matrix. However, a particular attention in FTIR analysis was the appearance of new peak at $620 \mathrm{~cm}^{-1}$ in the spectra of powder annealed at $1000^{\circ} \mathrm{C}$ and the peaks at $1100 \mathrm{~cm}^{-1}, 792 \mathrm{~cm}^{-1}$ and $490 \mathrm{~cm}^{-1}$ become narrower. This behavior is related to cristobalite phase of silica ${ }^{23}$, which proves that crystallization of silica occurs at $1000{ }^{\circ} \mathrm{C}$ in the silver silica nanocomposites. This obsevation is completely identical with XRD data.

\subsubsection{Raman Spectroscopy}

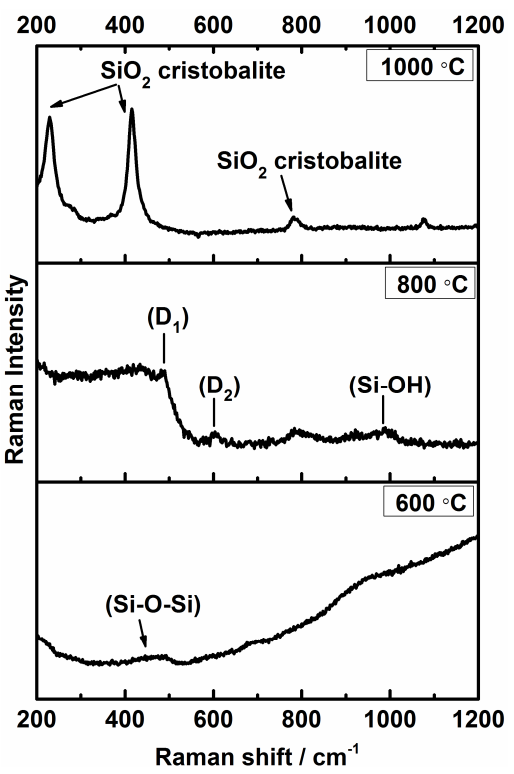

Figure 4. Raman spectra of the samples annealed at $600{ }^{\circ} \mathrm{C}, 800{ }^{\circ} \mathrm{C}$ and $1000^{\circ} \mathrm{C}$ for $1 \mathrm{~h}$

Raman techniques were also used to study the structural evolutions of silica matrix caused by the presence of silver particles as a function of the annealing temperatures. Fig. 4 shows the Raman spectra of the powders heat-treated at temperatures ranging from $600{ }^{\circ} \mathrm{C}$ to $1000{ }^{\circ} \mathrm{C}$. For the sample heat-treated at $600{ }^{\circ} \mathrm{C}$, the great quantity of residual organic reactants in the samples was able to result in a high level of spectral fluorescence. The featured bands for the amorphous nature of silica were observed in the system heat-treated at $800{ }^{\circ} \mathrm{C}$. The band at $440 \mathrm{~cm}^{-1}$ is attributed to bending mode of Si-O-Si. The $\mathrm{D}_{1}$ and $\mathrm{D}_{2}$ bands at 487 and $602 \mathrm{~cm}^{-1}$, are assigned to symmetric breathing modes of four-membered and three-membered rings of $\mathrm{SiO}_{2}$ tetrahedra, respectively. The band at $783 \mathrm{~cm}^{-1}$ corresponds to the motion of silicon against its tetrahedral oxygen cage. Finally, the band at $980 \mathrm{~cm}^{-1}$, which is related to vibrations of $\mathrm{Si}-\mathrm{OH}$ groups ${ }^{24}$, decreases in intensity with increasing annealing temperatures indicating the gradual removal of the 
solvent and precursor molecules.

It can be seen that there is a remarkable change in the spectral features between samples heated at $800{ }^{\circ} \mathrm{C}$ and $1000{ }^{\circ} \mathrm{C}$. In the top spectrum, the appearance of the most intense peaks centered at $230 \mathrm{~cm}^{-1}, 416 \mathrm{~cm}^{-1}$ and the least significant at $784 \mathrm{~cm}^{-1}$ can be interpreted as signatures of the $\mathrm{SiO}_{2}$ cristobalite structure ${ }^{23}$. This observation confirms clearly that the phase transformation of silica occurs at $1000^{\circ} \mathrm{C}$. This finding supports the results from the XRD and FTIR analysis, as has been described previously.

\subsection{Textural Properties}

In order to verify the effect of the growth of silver crystals on the porosity of the xerogels, nitrogen adsorption-desorption isotherms were recorded.

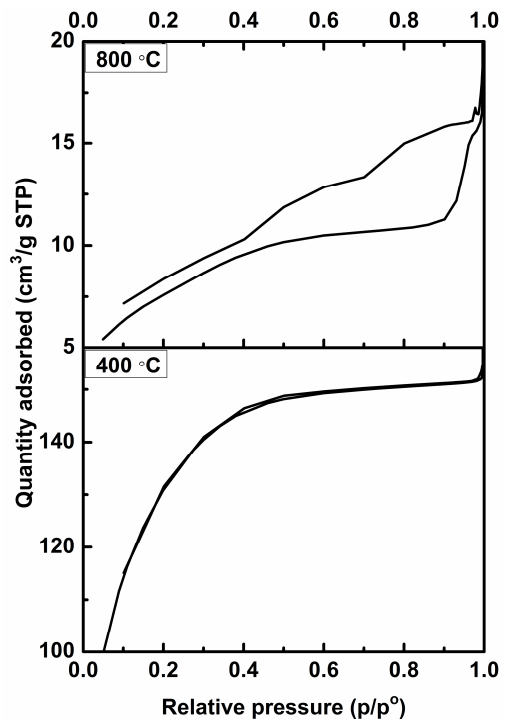

Figure 5. Nitrogen adsorption-desorption isotherms for the $\mathrm{SiO}_{2}-5 \% \mathrm{Ag}$ powder heat-treated at $400{ }^{\circ} \mathrm{C}$ and $800^{\circ} \mathrm{C}$ for $1 \mathrm{~h}$

From Fig. 5, it can be clearly seen that the nitrogen adsorption isotherm of the sample heat-treated at $400{ }^{\circ} \mathrm{C}$ can be classified as type I, which is typical for microporous absorbent. However, a type-IV isotherm is observed for the powder annealed at $800{ }^{\circ} \mathrm{C}$ (according to IUPAC classification). In the latter case, the isotherm exhibits a hysteresis loop, i.e. the adsorption and desorption isotherms do not coincide over a certain region of external pressures. This loop is characteristic of mesoporous samples with interconnected pores. The analysis of the adsorption-desorption isotherms shows that the average pore diameter after a calcination at low temperature remains at about $22 \AA$, while this value reaches $39 \AA$ in the system treated at higher heat-treatment. The TEM and XRD analyses illustrated that the increase in annealing temperature induces precipitation of bigger silver nanoparticles in the pores of silica. The presence and coarsening of Ag particles within channels of pore or between pores result in more and more isolated and unmeasured free spaces. That is the reason that the size of pores for the sample annealed at $800{ }^{\circ} \mathrm{C}$ is nearly twice as large as that of pores after heated at $400{ }^{\circ} \mathrm{C}$. This increment leads to remarkable decrease of surface area from $433.8 \mathrm{~m}^{2} / \mathrm{g}$ to $27.7 \mathrm{~m}^{2} / \mathrm{g}$.

\section{Conclusion}

Using a sol-gel technique, the $\mathrm{Ag} / \mathrm{SiO}_{2}$ nanocomposites have been successfully fabricated without protecting agents. TEM data present a relatively homogenous distribution of spherical silver nanoparticles throughout the amorphous silica network and the size ranges between 20 and $40 \mathrm{~nm}$ after a heat-treated at $800{ }^{\circ} \mathrm{C}$ for $1 \mathrm{~h}$ in air. Combination of XRD and TEM analyses with data of FT-IR and Raman spectroscopies show that the formation of silver nanocrystals results in significant decrease in crystalline temperature of silica matrix. In addition, the growth of silver particles with annealing temperatures has no effect on the densification of silica and leads to decrease the specific surface area. These powders will be the potential materials for antibacterial activity.

\section{Acknowledgement}

This work was supported by the Advanced Materials Laboratory, HCMíC University of Science, Vietnam National University and International Training Institute for Materials Science, Ha Noi University of Science and Technology.

\section{References}

[1] R. J. Chimentão, I. Kirm, F. Medina, X. Rodríguez, Y. Cesteros, P. Salagre, J. E. Sueiras, J. L. G. Fierro, "Sensitivity of styrene oxidation reaction to the catalyst structure of silver nanoparticles" Appl. Surf. Sci., vol. 252, pp. 793-800, 2005.

[2] N. Baheiraei, F. Moztarzadeh, and M. Hedayati, "Preparation and antibacterial activity of $\mathrm{Ag} / \mathrm{SiO}_{2}$ thin film on glazed ceramic tiles by sol-gel method", Ceram. Int., vol. 38, pp. 2921-2925, 2012.

[3] L. Guo, A. Guan, X. Lin, C. Zhang, and G. Chen, "Preparation of a new core-shell $\mathrm{Ag} @ \mathrm{SiO}_{2}$ nanocomposite and its application for fluorescence enhancement", Talanta vol. 82, pp. 1696-1700, 2010.

[4] S. Long, L. Li, H. Guo, W. Yang, and F. Lu, "Preparation of stable core-shell dye adsorbent Ag-coated silica nanospheres as a highly active surfaced-enhanced Raman scattering substrate for detection of rhodamine 6G", Dye. Pigment, vol. 95, pp. 473-477, 2012.

[5] P. Amornpitoksuk, S. Suwanboon, S. Sangkanu, A. Sukhoom, N. Muensit, and J. Baltrusaitis,"Synthesis, characterization, photocatalytic and antibacterial activities of Ag-doped $\mathrm{ZnO}$ powders modified with a diblock copolymer", Powder Technol., vol. 219, pp. 158-164, 2012.

[6] B. Sun, S. Sun, T. Li, and W. Zhang,"Preparation and antibacterial activities of $\mathrm{Ag}$-doped $\mathrm{SiO}_{2}-\mathrm{TiO}_{2}$ composite films by liquid phase deposition (LPD) method", J. Mater. Sci., vol. 42, pp. 10085-10089, 2007. 
[7] N. Sobana, M. Muruganadham, and M. Swaminathan,"Nano-Ag particles doped $\mathrm{TiO}_{2}$ for efficient photodegradation of direct azo dyes". J. Mol. Catal. A Chem., vol. 258, pp. 124-132, 2006.

[8] M. Kawashita, S. Tsuneyama, F. Miyaji, T. Kokubo, H. Kozuka, and K. Yamamoto, "Antibacterial silver-containing silica glass prepared by sol-gel method", Biomaterials, vol. 21, pp. 393-398, 2000.

[9] H. Jia, W. Hou, L. Wei, B. Xu, and X. Liu, "The structures and antibacterial properties of nano- $\mathrm{SiO}_{2}$ supported silver/zinc-silver materials", Dent. Mater., vol. 24, pp. 244-249, 2008.

[10] S. Duhan, S. Devi, and M. Srivastava, "Characterization of nanocrystalline $\mathrm{Ag} / \mathrm{SiO}_{2}$ nanocomposites and synthesis by wet chemical method", Indian J. Pure Ap. Phy., vol. 48, pp. 271-275, 2010.

[11] B. Mahltig, H. Haufe, K. Muschter, A. Fischer, Y.H. Kim, E. Gutmann, M. Reibold, D.C. Meyer, T. Textor, C.W. Kim, and Y.S. Kang,"Silver nanoparticles in $\mathrm{SiO}_{2}$ microspheres preparation by spray drying and use as antimicrobial agent". Acta Chim. Slov. vol. 57, pp. 451-457, 2010.

[12] Y.K. Mishra, S. Mohapatra, D. Kabiraj, B. Mohanta, N.P. Lalla, J.C. Pivin, and D.K. Avasthi,"Synthesis and characterization of Ag nanoparticles in silica matrix by atom beam sputtering", Scr. Mater., vol. 56, pp. 629-632, 2007.

[13] H.-J. Jeon, S.-C. Yi, and S.-G. Oh , "Preparation and antibacterial effects of $\mathrm{Ag}-\mathrm{SiO}_{2}$ thin films by sol-gel method", Biomaterials, vol. 24, pp. 4921-4928, 2003.

[14] K. S. Chou, C. C. Chen, "Fabrication and characterization of silver core and porous silica shell nanocomposite particles", Micropor. Mesopor. Mat., vol. 98, pp. 208-213, 2007.

[15] A. A. El-kheshen, S. F. G. El-rab, "Effect of reducing and protecting agents on size of silver nanoparticles and their anti-bacterial activity", Der. Pharma. Chemica., vol. 4, pp. 53-65, 2012.
[16] M. G. Guzmán, J. Dille, S. Godet, "Synthesis of silver nanoparticles by chemical reduction method and their antibacterial activity", Int. J. Chem. Biomolecular Eng., vol. 2-3, pp. 104-111, 2009.

[17] A. Chahadih, H. El Hamzaoui, O. Cristini, L. Bigot, R. Bernard, C. Kinowski, M. Bouazaoui, B. Capoen, " $\mathrm{H}_{2}$-induced copper and silver nanoparticle precipitation inside sol-gel silica optical fiber preforms" Nanoscale Res. Lett., vol. 7, pp. 487, 2012.

[18] A. Hilonga, J. K. Kim, P. B. Sarawade, D. V. Quang, G. Shao, G. Elineema, H. T. Kim, "Silver-doped silica powder with antibacterial properties", Powder Technol., vol. 215-216, pp. 219-222, 2012.

[19] Surender Duhana, N. Kishoreb, P. Aghamkarc, Sunita Devi, "Preparation and characterization of sol-gel derived silver-silica nanocomposite", J. Alloys and Compounds, Vol. 57, pp. 101-104, 2010

[20] D. C. Ram, "Microstructure and surface morphology of nanocrystalline silver silicates", Acta Physica Polonica A, vol. 121, pp. 2000-2002, 2012.

[21] L. L. Díaz-Flores, M. G. Garníca-Romo, J. González-Hernández, J. M. Yáñez-Limón, P. Vorobiev, Y. V. Vorobiev, "Formation of Ag-Cu nanoparticles in $\mathrm{SiO}_{2}$ films by sol-gel process and their effect on the film properties", Phys. Status Solidi, vol. 4, pp. 2016-2020, 2007.

[22] B. Akkopru, C. Durucan, "Preparation and microstructure of sol-gel derived silver-doped silica", J. Sol-Gel Sci. Technol., vol. 43, pp. 227-236, 2007.

[23] J. Mitra, M. Ghosh, R. K. Bordia, A. Sharma, "Photoluminescent electrospun submicron fibers of hybrid organosiloxane and derived silica", RSC Adv., vol. 3, pp. $7591,2013$.

[24] T. T. Van Tran, T. Si Bui, S. Turrell, B. Capoen, P. Roussel, M. Bouazaoui, M. Ferrari, O. Cristini, C. Kinowski, "Controlled $\mathrm{SnO}_{2}$ nanocrystal growth in $\mathrm{SiO}_{2}-\mathrm{SnO}_{2}$ glass-ceramic monoliths", J. Raman Spectrosc., vol. 43, pp. 869-875, 2012. 